\title{
A vida na rua como paradigma-matrioshka
}

\author{
Life on the street as matryoshka-paradigm
}

\author{
La vida en la calle como paradigma-matriosh ka
}

João Aldeia ${ }^{2}$

\begin{abstract}
Resumo: Este texto expõe uma posição metodológica. A vida na rua é menos interessante como objeto de estudo fechado sobre si mesmo do que como meio para aceder ao mundo em que existe. Enquanto objeto analítico, a vida na rua pode ser metodologicamente entendida como um paradigma (um exemplar) multidimensional cujo estudo permite compreender diversos dos fenómenos sociais mais relevantes no modelo societal moderno ocidental. Com este posicionamento em mente, a sociologia da vida na rua é substituída por uma sociologia que opera através da vida na rua, usando este fenómeno para abordar o universo de relações de poder que caracterizam este modelo societal. Sem pretender avançar uma lista exaustiva dos fenómenos que podem ser compreendidos através dela, entre as várias expressões do poder que são acessíveis pelo estudo da vida na rua, contemplam-se a pobreza, a vida do homo sacer na exceção permanente e o governo da alteridade desqualificada.
\end{abstract}

Palavras-chave: Metodologia; Paradigma; Pobreza; Poder; Vida na rua.

Abstract: This text presents a methodological position. Homelessness is less interesting as a study object closed around itself than as a means to access the world in which it exists. As an analytical object, homelessness can be methodologically understood as multidimensional paradigm (an exemplar) whose study allows us to understand several of the most relevant social phenomena in the Western modern societal model. With this positioning in mind, the sociology of homelessness is replaced by a sociology that works through homelessness, using this phenomenon to approach the set of power relations that characterize this societal model. Without intending to put forward an exhaustive list of phenomena that can be understood through it, among the various expressions of power that are accessible by the study of homelessness one can count poverty, the life of homo sacer in a state of permanent exception, and the government of disqualified otherness.

Keywords: Methodology; Homelessness; Paradigm; Poverty; Power.

\footnotetext{
${ }^{1}$ Este texto é uma versão revista de uma parte da minha tese de doutoramento em sociologia (Aldeia, 2016). A investigação foi realizada na Faculdade de Economia da Universidade de Coimbra, com o acolhimento científico do Centro de Estudos Sociais da mesma universidade, e financiada pela Fundação para a Ciência e a Tecnologia com a bolsa individual de doutoramento com a referência SFRH/BD/85867/2012. Agradeço a Sílvia Portugal, orientadora científica da pesquisa, e Ana Manso pela leitura da versão do texto que surge na tese e pelos seus comentários. Todos os problemas que permaneçam são da minha responsabilidade.

${ }^{2}$ Universidade de Coimbra (Coimbra, Portugal).

autor.dados_biográficos
}

Civitas, Porto Alegre, v. 19, n. 1, p. 213-229, jan.-abr. 2019

Este artigo está licenciado sob forma de uma licença Creative Commons Atribuição 4.0 Internacional, que permite uso irrestrito, distribuição e reprodução em qualquer meio, desde que a publicação original seja corretamente citada. https://creativecommons.org/licenses/by/4.0/deed.pt BR 
Resumen: Este texto expone una posición metodológica. La vida en la calle es menos interesante como objeto de estudio cerrado sobre sí mismo que como medio para acceder al mundo en que existe. Como objeto analítico, la vida en la calle puede ser metodológicamente entendida como un paradigma (un ejemplar) multidimensional cuyo estudio permite comprender diversos de los fenómenos sociales más relevantes en el modelo societal moderno occidental. Con este posicionamiento en mente, la sociología de la vida en la calle es sustituida por una sociología que trabaja a través de la vida en la calle, utilizando este fenómeno para abordar el universo de relaciones de poder que caracterizan este modelo societal. Sin pretender avanzar una lista exhaustiva de los fenómenos que pueden ser comprendidos a través de ella, entre las varias expresiones del poder que son accesibles por el estudio de la vida en la calle, se contemplan la pobreza, la vida del homo sacer en la excepción permanente y el gobierno de la alteridad descalificada.

Palabras clave: Metodología; Paradigma; Pobreza; Poder; Vida en la calle.

\section{Sociologia através da vida na rua}

A vida na rua apresenta-se como ponto de condensação de uma multiplicidade de processos sociopolíticos contemporâneos, adquirindo a forma de uma síntese sociológica. Deste modo, ela surge como uma atualização (e complexificação) moderna líquida da pobreza tal como esta foi abordada por Simmel (2008). O que este autor apresenta em Der Arme, originalmente publicado em 1908, não é uma sociologia da pobreza mas, antes, uma conceptualização da pobreza como um objeto de síntese sociológica. Em Simmel, a pobreza é um fenómeno que permite observar o funcionamento estrutural e interaccional da sociedade em geral. Para o autor,

a classe dos pobres constitui, em particular na sociedade moderna, uma síntese sociológica única. No que diz respeito à sua significação e ao seu lugar no corpo social, ela possui uma grande homogeneidade; mas, naquilo que é da qualificação individual dos seus elementos, esta falta-lhe completamente. É um fim comum para os mais diversos destinatários, um oceano no qual as vidas, derivadas das mais diversas camadas sociais, flutuam juntamente. Nenhuma mudança, nenhum desenvolvimento, nenhuma polarização ou rutura de vida social sobrevive sem deixar o seu resíduo na classe pobre (Simmel, 2008, p. 100-101). ${ }^{1}$

Portanto, para Simmel (2008), não está nunca em causa uma sociologia da pobreza mas, antes, uma sociologia que opera através da pobreza. Ao apresentar-se como fenómeno de síntese sociológica, a pobreza revela que

\footnotetext{
${ }^{1}$ Todas as citações em língua original que não o português foram por mim traduzidas.
} 
vários dos processos sociais - formas de interação, circulações de saber, relações de poder e de dominação, modos de subjetivação - mais relevantes para a caracterização e compreensão de um modelo societal particular operam no seu seio, é certo que de (e com) uma forma particular, mas que permite, contudo, observá-los a nu, i.e., na sua máxima intensidade. Caso sejam tomados outros objetos como ponto de partida e de análise, estas lógicas sociais surgem como que disfarçadas, matizadas por outros fatores que, não sendo, em definitivo, mera circunstância ou paisagem, não sendo insignificantes, dificultam a observação e compreensão daquilo que na pobreza se revela em toda a sua intensidade e violência.

Compreendendo a sociologia como a área disciplinar que estuda os fenómenos diferenciais de poder que ocorrem nas ações e interações humanas tal como estas se apresentam na modernidade, basicamente, a sociologia tem de ser entendida como a área de saber que estuda a relação com a alteridade. A alteridade não é mera diferença: é fenómeno de qualificação. Quando a diferença não implica um processo simétrico de qualificação/desqualificação, quando não se constitui em desigualdade, estamos a tratar de relações entre iguais -apesar da sua diferença formal-, pelo que os diferenciais de poder não são tão gritantes, tornando-se, por este motivo, menos relevantes. Se a dominação é uma relação de poder desigual de um modo tão elevado e contínuo que se constitui em injustiça e/ou imoralidade, colocando em causa as possibilidades de vida dos sujeitos prejudicados na interação, só na relação com o outro ela se torna no centro da análise.

Ora, é na pobreza que tal forma dos diferenciais de poder surge na sua intensidade não disfarçada. Mas como estes diferenciais de poder não são idiossincráticos da pobreza, olhar para ela é olhar para o poder através dela, olhar para o poder no ponto em que este se liberta dos constrangimentos operacionais a que é forçado e a que se força noutras esferas da sociedade.

Enquanto síntese sociológica, a pobreza revela que certos processos sociais fundamentais para a compreensão do modelo societal do ocidente norte moderno convergem para um locus específico, para a relação com os pobres, sempre desqualificados (o que é apenas um modo particular de os qualificar). E, para aí convergindo, nela tomam forma, despidos. Porém, precisamente devido a essa convergência, estes fenómenos sociais, estas relações, ganham na pobreza uma nova forma, não inteiramente idiossincrática mas com especificidades, expondo-a como objeto de síntese. Ao convergirem para a relação com os pobres, diversas formas de poder aí se articulam de modo 
agonístico, desenvolvendo-se e modificando-se continuamente, dando forma à pobreza.

Se se aceitar que a pobreza funciona assim, que ela é isto, então, é defensável argumentar que a vida na rua é uma manifestação particularmente dramática, particularmente intensa do fenómeno mais geral que é a pobreza. Já Simmel (2008, p. 99), no início do século 20, assim conceptualizava a falta de abrigo, considerando-a como "o resultado do fenómeno extremo da pobreza".

Nesta medida, a pobreza pode ser entendida como paradigma de todo o modelo societal em que existe e, de modo logicamente derivativo, a vida na rua pode ser compreendida como paradigma do paradigma que é a primeira. Enquanto fenómeno de síntese sociológica, a vida na rua é, contudo, compreensível como um paradigma de tipo especial. Ao agregar em si diversos outros fenómenos sociológicos fundamentais do mundo contemporâneo, a vida na rua revela-se como paradigma-matrioshka, i.e., como um tipo de paradigma que contém dentro de si mesmo outros paradigmas. Através de um posicionamento metodológico assente na analogia, e não na representatividade, torna-se possível abandonar a posição solipsista de um método que postula que os estudos sociais devem abordar fenómenos-objetos concretos (a pobreza, a arte, o trabalho, o direito, a família, o estado, o Terceiro Setor, a toxicodependência, a prostituição etc.). Bem pelo contrário, numa metodologia analógica, o caráter concreto do campo que é a vida na rua serve como ponto de observação do único fenómeno-objeto sociologicamente relevante: o próprio processo de contínua produção societal através de interações em que se confrontam posições reticulares de poder desiguais. Como paradigmamatrioshka, a vida na rua é sociologicamente interessante não em si mesma mas como caminho, estrada, canal ou ponte que, sendo percorrida com atenção, permite compreender o mundo através de si. Rejeitando a representatividade, deixa de ser possível ou relevante realizar uma sociologia $d a$ vida na rua, sendo esta substituída por outra coisa. Querendo chamar-lhe algo - e não é de todo necessário que tal ocorra -, o método analógico ancorado na ideia de paradigma-matrioshka é o percurso daquilo que, apelando à herança simmeliana, se pode designar como uma sociologia através da vida na rua. Isto não significa que as especificidades do objeto ou dos campos específicos que são abordados sejam desconsideradas. Realizar uma sociologia através da vida na rua indica somente que, ao estudar esta última, o conhecimento produzido não permite apenas elucidar este fenómeno mas, ultrapassando-se a si mesmo, torna possível compreender aquilo que a vida na rua diz sobre o mundo em que existe. 


\section{Paradigmas}

Apesar do próprio Kuhn (2009, p. 277-279) frisar que as suas reflexões em The structure of scientific revolutions não devem ser simplesmente retiradas do seu contexto de aplicação na história das ciências naturais e transpostas para outros campos disciplinares, conceitos como os de ciência normal, revolução científica ou paradigma apresentam elevado valor heurístico para a compreensão sociológica do mundo - desde que mobilizados com o necessário rigor metodológico. A noção de paradigma é particularmente útil para a reflexão sobre a vida na rua, servindo de alavanca metodológica para passar desta última para uma reflexão sobre o mundo através da vida na rua. Para Kuhn (2009, p. 13), “os paradigmas são [...] realizações científicas que durante um certo período fornecem problemas e soluções-modelo para uma comunidade de especialistas". Porém, como Agamben (2009a) discute no seu texto What is a paradigm?, Kuhn mobiliza o termo em dois sentidos distintos, ainda que articulados. O próprio Kuhn (2009, p. 235-279), no posfácio de 1969 à sua obra, explicita esta dupla significação do termo, escrevendo que ele,

por um lado, representa uma constelação de crenças, valores, técnicas, etc., compartilhadas pelos membros de uma dada comunidade. Por outro lado, denota um certo tipo de elemento no interior dessa constelação, as resoluções de enigmas já concretizadas que, servindo de modelos ou exemplos, podem substituir regras explícitas como base para a resolução de outros enigmas da ciência normal que ainda estão para resolver (Kuhn, 2009, p. 236).

Segundo o autor, a primeira aceção do termo corresponde ao seu sentido sociológico, remetendo a segunda para a ideia de paradigmas enquanto realizações científicas exemplares (Kuhn, 2009, p. 236). Pace Kuhn, ambos os sentidos do termo paradigma por ele mobilizados são inerentemente sociológicos, ainda que remetam para níveis diferentes de construção (no sentido de enactment $)^{2}$ da realidade. O primeiro sentido do termo, que Kuhn (2009) usa como sinónimo de matriz disciplinar, é extraordinariamente semelhante, quase sobreponível, ao conceito foucaultiano de regime de verdade (Foucault, 1980a; 1994, passim; 1999, p. 7 et seq.; 2005; 2010, p. 57 et seq.; 2012). Como Kuhn escreve, um paradigma é uma matriz disciplinar em sentido rigoroso:

\footnotetext{
${ }^{2}$ Acerca da noção de enactment $\mathrm{e}$, em particular, no que respeita à sua diferença relativamente à noção de construction, cf. Law (2004) e Mol (2002).
} 
disciplinar, porque se refere àquilo que os que põem em prática uma disciplina determinada possuem em comum; matriz, porque corresponde a uma ordenação de elementos de índole variada, cada um deles exigindo especificação ulterior (Kuhn, 2009, p. 245).

Ora, o segundo sentido do termo não revela menos relevância sociológica, sobretudo, para uma sociologia assente na analogia e que, definitivamente, recuse a pretensão de representatividade. Nesta segunda aceção, um paradigma é um exemplo partilhado por uma comunidade paradigmática, que se associa precisamente em torno da partilha do paradigma-exemplo (Kuhn, 2009, p. 251257 et passim). A etimologia de paradigma remete de modo direto para este segundo significado do termo. Paradigma deriva do grego paradeiknunai, literalmente, para, "ao lado", e deiknunai, "mostrar", logo, "mostrar ao lado", indicando a ideia de aprendizagem pela imitação de um exemplo (Schram, 2006, p.32). Neste sentido etimológico, um paradigma é um exemplar, portanto, no sentido latino clássico, é algo que "pode ser observado pelos sentidos", é "oculis conspicitur", e que se deve imitar, "exemplar est quod simile faciamus" (Agamben, 2009a, p. 18).

Estes exemplos antecedem quer as regras da prática disciplinar quer as teorias vigentes na área de saber (Kuhn, 2009, p. 72 et seq., 251-257). Antes da incorporação (mais ou menos reflexiva) destas regras e teorias, os sujeitos que integram uma comunidade paradigmática aprendem, por processos nem sempre inteiramente conscientes, a identificar semelhanças de família entre fenómenos e entidades e é esta identificação que lhes permite, a partir de um caso paradigmático (logo, exemplar), perceber outros casos, outros problemas. Ou seja, numa lógica wittgensteiniana, Kuhn (2009, p. 75-77) defende que os sujeitos identificam que certas coisas pertencem à mesma classe não por reconhecerem de modo explícito as suas características comuns e exclusivas (que podem nem sequer existir) mas, antes, porque, tacitamente, com base na sua experiência, sentem a sua "parecença de família".

Pela identificação de tais isomorfismos, as duas aceções kuhnianas do termo paradigma sobrepõem-se, articulam-se e reforçam-se mutuamente: ao identificarem uma semelhança de família entre fenómenos e/ou entidades, i.e., ao reconhecerem um isomorfismo fundamental entre um fenómeno com que se deparam e outro, que tem valor paradigmático, os sujeitos remetemnos para o mesmo paradigma-como-sinónimo-de-regime-de-verdade, para uma mesma mundivisão, para uma mesma gestalt. Nas palavras de Kuhn, os estudantes de uma ciência (ou, ampliando o argumento, de uma área disciplinar) 
referem regularmente que, ao lerem um capítulo do seu manual, percebem-no perfeitamente, mas sentem, apesar disso, dificuldades em resolver os exercícios que encontram no fim do capítulo. Em geral, as dificuldades acabam por se dissolver do mesmo modo. $\mathrm{O}$ estudante descobre, com ou sem ajuda do seu professor, uma forma de ver o problema como se este fosse um problema com que já se tivesse deparado. Ao ver a parecença e ao aperceber-se da analogia entre dois ou mais problemas distintos, pode estabelecer relações entre os símbolos e relacioná-los com a natureza pelas vias que no passado se tinham revelado eficazes. $\mathrm{O}$ esboço de lei, digamos $\mathrm{f}=\mathrm{ma}$ [segunda lei do movimento de Newton], funcionou como ferramenta, informando o estudante sobre que semelhanças procurar e indicando a gestalt sob a qual a situação deve ser vista. A consequente aptidão para perceber as parecenças entre situações várias e para vê-las como instâncias de $\mathrm{f}=$ ma ou de outra generalização simbólica é, na minha opinião, aquilo que de mais importante o estudante retira da prática com problemas exemplares, seja a prática de papel e lápis, seja a realizada num laboratório sofisticado. Depois de ter completado um certo número de problemas, número que pode grandemente variar de indivíduo para indivíduo, passa a olhar para as situações que se lhe deparam com a mesma gestalt que outros membros do seu grupo de especialistas. Doravante, essas situações já não são para ele aquelas que encontrou quando iniciou a sua formação. Assimilou entretanto um modo de ver que foi testado pelo tempo e autorizado pelo grupo (Kuhn, 2009, p. 254).

Portanto, o conhecimento e a forma de prática específicas de uma área disciplinar são adquiridos não tendo como primeiro momento incontornável a assimilação de teoria mas, pelo contrário, pela aprendizagem praxiológica da identificação (progressivamente automatizada) de relações de similaridade entre fenómenos (situações, problemas e/ou entidades). Este processo de mobilização de paradigmas revela o caráter ${ }^{3}$ do saber específico de uma área disciplinar: "aprender com os problemas a descobrir parecenças entre situações diferentes, a vê-las como objectos aos quais se pode aplicar a mesma lei científica ou esboço de lei", indicando

um conhecimento da natureza significativo, adquirido quando se aprende a estabelecer relações de similaridade - conhecimento a partir daí impregnado num modo de ver as situações físicas -, em vez de um conhecimento adquirido através de regras ou leis (Kuhn, 2009, p. 254).

\footnotetext{
${ }^{3}$ A sua forma mais do que o seu conteúdo, no sentido que Simmel (s. d., p.21-23 et passim) dá aos termos.
} 
Tal não invalida a existência de regras teóricas ou práticas (e a distinção entre estas é puramente analítica, não empírica) mas indica que os paradigmascomo-exemplares apresentam uma anterioridade processual face às primeiras, que apenas podem ser derivadas a posteriori da identificação de relações de similaridade permitida pelos paradigmas (ainda que, muitas vezes, o contexto de justificação do saber de uma disciplina inverta a causalidade entre os dois momentos).

No seguimento da conceptualização kuhniana, Agamben (2009a) defende que ele próprio tem abordado conceitos como homo sacer, muselmann, estado de exceção ou campo como paradigmas no segundo sentido kuhniano do termo. Como o próprio afirma,

apesar de todos estes [conceitos] serem fenómenos históricos reais, tratei-os como paradigmas cuja função era constituir e tornar inteligível um contexto histórico-problemático mais vasto (Agamben, 2009a, p. 9).

Neste sentido, Agamben (2009a) posiciona-se como herdeiro metodológico de Foucault, trabalhando tal como este último pela mobilização de figuras epistemológicas (o louco, o panóptico, o anormal, a sexualidade, o pastorato, etc.) que estão próximas do significado kuhniano de paradigmacomo-exemplar (Agamben, 2009a, p. 17). ${ }^{4}$ Ainda, segundo o autor, mesmo não mobilizando o conceito, os paradigmas podem ser compreendidos como

o gesto mais característico do método de Foucault. O grande encarceramento, a confissão, a investigação, o exame, o cuidado de si: todos eles são fenómenos históricos singulares que Foucault trata como paradigmas, e isto é o que constitui a sua intervenção específica no campo da historiografia. Os paradigmas estabelecem um contexto problemático mais vasto, que tanto constituem quanto tornam inteligível (Agamben, 2009a, p. 17).

Os paradigmas são o ponto de ancoragem de uma metodologia que privilegia a analogia, usando a exemplaridade como processo de elucidação da realidade. Neste sentido, o autor distingue-os da metáfora:

os paradigmas obedecem não à lógica da transferência metafórica de significado mas à lógica analógica do exemplo. Aqui não estamos a lidar com um significante que é estendido para designar

\footnotetext{
${ }^{4}$ Tal não invalida que existam diferenças metodológicas substanciais entre Agamben e Foucault. Não obstante, a mobilização de uma metodologia paradigmática para abordar relações de biopoder aproxima-os suficientemente para que faça sentido articular os seus pensamentos.
} 
fenómenos heterogéneos com base na mesma estrutura semântica; mais aparentado [akin] à alegoria do que à metáfora, o paradigma é o caso singular que é isolado do seu contexto apenas na medida em que, exibindo a sua própria singularidade, torna inteligível um novo conjunto, cuja homogeneidade ele próprio constitui. Ou seja, dar um exemplo é um ato complexo que supõe que o termo que funciona como paradigma é desativado do seu uso normal, não para ser movido para outro contexto mas, pelo contrário, para apresentar o cânone - a regra - desse uso, que não pode ser mostrado de qualquer outro modo (Agamben, 2009a, p. 18).

Segundo este argumento, Agamben (2009a) remete a lógica exemplar dos paradigmas para fora da dicotomia universal/particular. Pura e simplesmente, as duas lógicas de pensamento são incomensuráveis e procurar fazer os paradigmas operar dentro desta dicotomia des-significa-os, elimina o seu valor metodológico. O paradigma, por definição, não obedece nem à lógica da indução nem à da dedução. Não partindo do particular para o universal nem do universal para o particular,

o paradigma é definido por um terceiro e paradoxal tipo de movimento, que vai do particular para o particular. O exemplo constitui uma forma de conhecimento particular que não procede articulando o universal e o particular mas parece permanecer [dwell] no plano deste último (Agamben, 2009a, p. 19).

Porém, se o paradigma anula o caráter universal do saber ao deslocar o âmbito da sua operação para fora dele, também não pode ser simplesmente reduzido ao outro termo da dicotomia (Agamben, 2009a, p. 19-20). O paradigma tem valor próprio fora dela, e esse valor é o da analogia, o da deslocação permanente de um particular logicamente isolado do fenómeno que o engloba para outro particular que ele permite elucidar - e, neste movimento, o paradigma realiza uma elucidação dupla: a do novo particular que constitui e explica (e.g., a vida na rua como paradigma das relações de poder em que está envolvida uma alteridade desqualificada) e a do fenómeno que inicialmente o engloba (pois, no movimento do particular para o particular, a empiria específica estudada elucida vida na rua e esta elucida a pobreza). Portanto, não se podendo posicionar nem no campo do universal nem no do particular tout court, e não obedecendo nem à lógica da dedução nem à da indução,

o paradigma implica um movimento que vai da singularidade para a singularidade e, sem nunca sair da singularidade, transforma cada caso singular num exemplar de uma regra geral que nunca pode ser enunciada a priori (Agamben, 2009a, p. 22). 
Esta regra geral não pode ser enunciada a priori, enfim, a classe de fenómenos a que o paradigma pertence e que ele permite compreender não pode ser referida sem a explicitação do próprio paradigma pois, em termos rigorosos, esta regra-classe não existe antes do paradigma - ainda que também o paradigma não tenha uma existência apriorística, pronta a ser usada. Ao ser enunciado, o fenómeno-paradigma elucida-se a si mesmo, permite a compreensão do campo de realidade que é. Mas, de modo adicional, este fenómeno, sendo paradigmático, ultrapassa-se a si mesmo e adquire valor heurístico para a compreensão de outras realidades, para a compreensão da classe de fenómenos a que pertence, que revela e que constitui. Esta classe de fenómenos só existe na exata medida em que é feita existir pela explicitação do paradigma, ou seja, “o grupo paradigmático nunca é pressuposto pelos paradigmas; antes, é imanente neles" (Agamben, 2009a, p. 31).

Contudo, em termos exatos, também o próprio paradigma não existe antes da sua exposição. O fenómeno paradigmático não é paradigma a priori mas, antes, é gerado como paradigma pelo próprio processo metodológico analógico. Nesta medida, a relação paradigmática é tripla. (1) É uma relação de analogia entre objetos particulares. Vai do particular para o particular. Mostra uma semelhança de família, uma relação de similaridade entre objetos particulares. (2) É uma relação entre um objeto particular e uma regra, fenómeno ou classe de fenómenos que não pode ser enunciada antes do paradigma ser mostrado. A regra, o fenómeno ou a classe de fenómenos existe porque existe o seu paradigma, não existindo a primeira antes do segundo ser revelado. (3) É uma relação entre um objeto particular e a sua exposição. Ou seja, este objeto (campo, relação, fenómeno etc.) é tornado paradigma precisamente ao ser tornado inteligível. O objeto não existe como paradigma antes de ser enunciado, exposto, revelado. Ele torna-se paradigma quando é gerado como tal. E, deste modo, a forma como o objeto é metodologicamente abordado é fundamental para que este possa ou não ser produzido como paradigma - claro está, dentro dos limites impostos pela necessidade da aceitação intersubjetiva deste objeto como paradigma pela comunidade paradigmática (Agamben, 2009a).

\section{O caráter multiparadigmático da vida na rua}

Ancorar metodologicamente o estudo da vida na rua na sua compreensão paradigmática, portanto, remete a investigação para uma herança intelectual clara, assente, sobretudo mas de modo não exclusivo, em Simmel e, principalmente, dado que sempre trabalharam com metodologias paradigmáticas (a loucura, a confissão, o homo sacer, o estado de exceção etc.), Agamben (2009a) e Foucault (1980a,1999, 2005, 2010, 2012). 
A compreensão da vida na rua como paradigma-matrioshka baseia-se em duas ideias. Por um lado, sobrepõem-se neste objeto de estudo diversos paradigmas. Por outro lado, nele coexistem também, de modo paralelo, paradigmas que, não se sobrepondo por completo, são tangenciais, operando lado a lado, tocando-se mas não se reduzindo inteiramente um ao outro, nenhum deles subsumindo o outro. Necessariamente, as duas aceções do termo paradigma (como gestalt e como exemplar) funcionam nesta reflexão em simultâneo e de forma articulada.

Como referi, a pobreza e a vida na rua apresentam-se como paradigmas sobrepostos, a primeira não se autorrepresentando de modo autopoiético mas, antes, permitindo aceder ao mundo mais vasto em que existe pela sua exposição e compreensão, e a segunda permitindo realizar um movimento isomórfico com a mediação do movimento anterior. Ou seja, é enquanto exemplar do exemplar que a vida na rua permite aceder ao mundo em que existe, nomeadamente, ao mundo no que neste diz respeito à(s) relação(ões) com a(s) alteridade(s) desqualificada(s).

Pelo que foi dito, a relação de pobreza pode ser interpretada como um quadro conceptual conducente à compreensão da vida na rua. Porém, uma metodologia analógica que entenda a vida na rua como paradigma-matrioshka inverte os termos desta relação explicativa. Só tal inversão confere ao método mobilizado um valor heurístico superior face ao procedimento mais habitual de interpretação de fenómenos como se fossem autorreferenciais pelo uso hipotético-dedutivo de um qualquer quadro conceptual. Não está em causa a defesa da maior validade deste ou daquele quadro teórico para perceber a vida na rua mas, bem pelo contrário, a apologia do uso desta última como forma de estudar o mundo em que existe. Assim, a questão metodológica basilar é entender a vida na rua como, entre outras coisas, $a$ forma par excellence da pobreza no ocidente norte contemporâneo. Ele não assume esta forma por ser o fenómeno quantitativamente mais representativo da pobreza. Este argumento, pura e simplesmente, não faz sentido se vida na rua é paradigma-matrioshka. A vida na rua é exceção e é precisamente por este seu caráter excecional que se torna no locus privilegiado onde pode ser observada a pobreza e/ou as relações de poder desiguais a um nível tal que se constituem em dominação. ${ }^{5}$

\footnotetext{
${ }_{5} \mathrm{O}$ caráter excecional da vida na rua não equivale a que ela seja atípica ou residual, mesmo a um nível quantitativo, nas sociedades ocidentais contemporâneas. Bem pelo contrário, seguindo o pensamento de Agamben $(1998,2010)$, umas das características fundamentais da exceção contemporânea é a sua normalização, conferindo-lhe uma forma permanente. Aliás, como Benjamin (2007, p. 257) recordou, este foi sempre o caso para os sujeitos dominados ao longo da história, que, vivendo na exceção, não experienciam tais formas de vida por períodos temporais limitados mas, pelo contrário, fazem-no de modo continuado.
} 
Ancorando a reflexão na herança de Schmitt (2005), Canguilhem (2007) e Agamben (1998, 2010), a exceção é percebida como mais interessante do que a regra, como mostrando mais do mundo do que a regra, dado que a regra só permite perceber a regra enquanto que a exceção demonstra na sua nudez não só a própria exceção quanto a regra que ela funda, revelando ainda a relação coconstitutiva, mutuamente fundadora, entre regra e exceção. É na exata medida em que a vida na rua é exceção, limiar, limite e caso extremo que ela revela os outros fenómenos de um modo particularmente propício à sua observação sociológica.

O papel da exceção na vida na rua, porém, não se esgota neste posicionamento metodológico, anunciando uma nova dimensão paradigmática. A vida na rua elucida a relação de dominação com a alteridade desqualificada mas fá-lo de modo mediado. Esta relação decorre no espaço da exceção permanente espacialmente localizada, decorre na "zona de indistinção" (Agamben, 1998; 2010), no locus em que a normatividade que rege as vidas dos cidadãos domiciliados deixa de se aplicar de facto e é substituída pelo arbítrio do exercício do poder.

No centro da exceção encontra-se uma figura, um arquétipo de sujeito, mas este não é diretamente o sujeito sem-abrigo. $\mathrm{O}$ outro desqualificado que está no centro da zona de indistinção é o homo sacer, o sujeito politicamente abandonado ao qual é negada toda e qualquer qualificação política (positiva) e cuja vida é exposta em toda a sua nudez à aleatoriedade com que outrem o pode matar sem cometer homicídio. No direito romano clássico, esta exposição absoluta do homo sacer ao exercício do poder decorre da sua dupla exclusão normativa. Esta figura sagrada - e logo, impura -, precisamente devido à sua sacralidade, não pode ser objeto de sacrifício ritual mas pode, contudo, ser morto indiscriminadamente. O homo sacer encontra-se fora do ius divinum, não podendo ser sacrificado aos deuses, e fora do ius humanum, levando a que o sujeito que o mata não possa ser julgado por homicídio (Agamben, 1998).

Esta forma de vida do homo sacer coloca-o numa posição idiossincrática. Face a ele, todos os outros sujeitos podem exercer uma prerrogativa soberana de "matar ou deixar viver" (Foucault, 1994, p. 137-138 et passim; 2006, p. 256-257 et passim), portanto, todos podem dar-lhe morte. Mas, ao mesmo tempo, ele é fundamentalmente incapaz de matar outrem pois este ato assenta na constituição do sujeito a matar como homo sacer, o que implica a mobilização da prerrogativa de "matar ou deixar viver", que está, por definição, vedada a quem é sacer (Agamben, 1998).

Se, numa primeira linha de compreensão, a vida na rua é paradigma da pobreza, que é paradigma da relação de dominação com a alteridade 
desqualificada, que é paradigma do exercício do poder no mundo contemporâneo, numa segunda linha conceptual, paralela ou mesmo tangencial à anterior, a vida na rua é também paradigma da relação de abandono político do homo sacer na exceção permanente que, por sua vez, é também ela paradigma do exercício do poder no mundo contemporâneo, levando a que os dois percursos paradigmáticos que se iniciam com a vida na rua, seguindo caminhos distintos mas entrecruzados, vão dar ao mesmo ponto final.

Em grande medida, esta segunda dimensão decorre do facto de, na praxis, o homo sacer ser uma entidade fundamentalmente heterogénea - não $o$ homo sacer mas diferentes tipos ou expressões de homines sacri -, o que permite perceber o sujeito sem-abrigo como uma das suas manifestações simbólicas basilares no presente, enfim, permite conceber o sujeito sem-abrigo como paradigma do homo sacer politicamente abandonado, aprisionado na exceção permanente e reduzido a uma vida nua. Tal como o sujeito sagrado, quem vive na rua é estruturalmente colocado numa posição na qual todos os nãosem-abrigo podem, arbitrariamente, - em diferentes graus - diminuir as suas possibilidades de vida. Mas, em simultâneo, esta mesma posição estrutural impede quem vive na rua de diminuir de modo significativo as possibilidades de vida dos sujeitos domiciliados. ${ }^{6}$

Ao ser paradigma da relação de dominação da alteridade desqualificada, a vida na rua, necessariamente, permite compreender a forma desta relação. $\mathrm{Na}$ sua dimensão propriamente sociológica, a vida na rua corresponde a um agregado de procedimentos, tecnologias, atores, discursos, instituições etc., reticularmente articuladas de forma agonística. Nesta medida, a vida na rua é na sua plenitude compreensível como equivalente ao dispositivo de governo da vida na rua, portanto, a rede composta por todos os elementos cuja ação, de modo direto ou indireto, explícito ou implícito, consciente ou inconsciente, contribui para dar uma forma social específica à vida na rua, forma essa que é dinâmica e apenas conhece estabilizações espácio-temporalmente contextuais e provisórias. ${ }^{7}$ Este dispositivo revela uma nova dimensão paradigmática ao, ultrapassando-se a si mesmo, ser um ponto de entrada analítico no estudo dos dispositivos de governo da alteridade desqualificada.

\footnotetext{
${ }^{6}$ Excetuando se quem vive na rua recorrer à violência física. Mas mesmo neste caso a diminuição de possibilidades de vida que um sujeito sem-abrigo pode gerar sobre um sujeito domiciliado tenderá a ser significativamente mais suave do que a resposta coletiva a este ato através das instituições repressivas (polícia, tribunais, prisão etc.).

${ }^{7}$ Uso o conceito de dispositivo (dispositif) na sua aceção foucaultina. Sobre esta conceptualização, para além do próprio Foucault (1980b; 1994), cf. Abadía (2003), Agamben (2009b), Binkley (2011), Deleuze (1992) e Raffnsøe, Gudmand-Høyer, Thaning (2014).
} 
Obviamente, a vida na rua não esgota o mundo. Não obstante, através dela, compreendendo-a como paradigma-matrioshka, é possível elucidar uma parcela do mundo bastante mais vasta, e fazê-lo de forma bastante mais precisa, do que se este fenómeno for pensado como foco em si mesmo da investigação. É certo que, por um lado, o dispositivo de governo da vida na rua tem especificidades que não se encontram noutros dispositivos (sem, contudo, ser completa idiossincrasia) e, por outro lado, estes últimos têm propriedades que não estão necessariamente presentes no primeiro. Porém, há um conjunto de propriedades interaccionais - respeitantes à forma dominante das interações de dominação, aos processos de saber que estas potenciam, aos exercícios de poder que estas efetivam e aos processos de subjetivação (e arquétipos de sujeito) que estas incentivam - que são incontornáveis em todos estes dispositivos (ou, pelo menos, numa parte significativa deles).

Sendo dispositivos de governo de alteridades desqualificadas, todos eles partilham uma lógica de ação que, tendo sem dúvida manifestações concretas distintas, assenta na modelação da conduta dos sujeitos mais fracos e na sua subjetivação como variações do que é possível entender como o sujeito-menosque, uma entidade permanentemente produzida como inferior face aos sujeitos positivamente valorizados segundos os critérios da norma científico-estatística e da normatividade jurídico-cultural dominantes. Intervindo sobre a vida destes sujeitos, quer como indivíduos, quer como coletividades, todos estes dispositivos se caracterizam pela mobilização de formas de ação biopolíticas pelas quais, exercendo um poder de "fazer viver ou rejeitar para a morte" (Foucault, 1994, p. 137 et seq., em particular, p. 140; 2006, p. 255 et seq.), procuram proteger e estimular certas formas de vida concretas, obedecendo a imperativos de normalização, desenvolvendo estratégias de (re)subjetivação e produzindo formas de saber (verdade) particulares que tendem para a exclusividade.

Estes processos de proteção e estímulo vital, porém, são sempre acompanhados pela anulação, proibição, dificultação e desincentivo do desenvolvimento de outras formas de vida e de subjetivação. Deste modo, tanto quanto biopolíticas, estas estratégias de governo da alteridade desqualificada revelam-se sempre, necessariamente, também tanatopolíticas (Agamben, 1998; Esposito, 2010a; 2010b; 2011). Em todos estes dispositivos, tanto quanto o governo da vida, está em causa o governo da morte - entendida, no seu sentido sociológico mais útil, ainda que não exclusivo, não como fim absoluto da vida biológica mas, antes, como diminuição permanente de possibilidades de vida, mesmo que isto mais não seja do que o complemento da criação e manutenção 
de outras possibilidades de outras formas de vida. Deslocando-se dos campos ideal típicos da vida e da morte tout court, é na sobrevivência - nas suas formas, nas suas barreiras, nas suas dificuldades, nas suas oportunidades - que se encontra o centro analítico do estudo sociológico dos dispositivos de governo da alteridade desqualificada. Ao afastar-se este quer do estudo pelo lado da vida (numa certa conceção biopolítica) quer do estudo pelo lado da morte (numa conceção tanatológica), a análise dirige-se para a compreensão das formas concretas de uma bio-tanato-política que, não matando simplesmente nem fazendo indiscriminadamente viver, faz sobreviver.

Tal como é possível estudar a pobreza ou o homo sacer a partir de outros paradigmas que não a vida na rua, também as estratégias bio-tanato-políticas pelas quais os diversos dispositivos de governo de alteridades desqualificadas fazem sujeitos-menos-que sobreviver podem ser estudadas sem passar por este fenómeno. Porém, ele é, sem dúvida, um dos campos em que todos estes processos governamentais se efetivam de modo mais claro, e logo, um daqueles em que o seu estudo pode ser mais frutuoso. Em grande medida, tal deve-se precisamente à forma de síntese sociológica que ele assume. Tanto na praxis quanto no discurso, a vida na rua é governada em permanente indeterminação com outros fenómenos. As estratégias de governo da doença mental, da toxicodependência, do alcoolismo, do desemprego, da assistência, da relação dos sujeitos com a habitação, o trabalho ou o estado são apenas algumas das mais óbvias, mas definitivamente não exclusivas, formas de ação que se refletem de modo inegável no governo da vida na rua. Adquirindo uma forma particular pela sua agregação num mesmo campo, todas estas decisões e ações sobre alteridades desqualificadas, contudo, não podem deixar de ser visíveis na vida na rua e as alterações nos campos próprios de cada uma delas acarretam consequências sobre ela, tornando-a, assim, num ponto privilegiado para a sua compreensão.

\section{Referências}

ABADÍA, Óscar Moro. ¿Qué es un dispositivo? Empiria: revista de metodología de Ciencias Sociales, v. 6, p. 29-46, $2003<10.5944 /$ empiria.6.2003.933>.

AGAMBEN, Giorgio. O poder soberano e a vida nua: homo sacer. Lisboa: Presença, 1998.

AGAMBEN, Giorgio. What is a paradigm? In: Giorgio Agamben. The signature of all things: on method. New York: Zone Books, 2009a. p. 9-32.

AGAMBEN, Giorgio. O que é um dispositivo? In: Giorgio Agamben. $O$ que é o contemporâneo? e outros ensaios. Chapecó: Argos, 2009b. p. 25-51.

AGAMBEN, Giorgio. Estado de excepção. Lisboa: Edições 70, 2010. 
ALDEIA, João. Governar a vida na rua: ensaio sobre a bio-tanato-política que faz os sem-abrigo sobreviver. Coimbra: Faculdade de Economia da Universidade de Coimbra, 2016. Tese de doutorado em Sociologia.

BINKLEY, Sam. Psychological life as enterprise: social practice and the government of neo-liberal interiority. History of the Human Sciences, v. 24, n. 3, p. 83-102, 2011 $<10.1177 / 0952695111412877>$.

BENJAMIN, Walter. Theses on the Philosophy of History. In: Walter Benjamin. Illuminations: essays and reflections. New York: Schocken Books, 2007 [ed. orig.: 1950]. p. 253-264.

CANGUILHEM, Georges. The normal and the pathological. New York: Zone Books, 2007 [ed. orig.: 1966].

DELEUZE, Gilles. What is a dispositif? In: Timothy J. Armstrong (org.). Michel Foucault: philosopher. New York: Routledge, 1992. p. 159-168.

ESPOSITO, Roberto. Bios: biopolítica e filosofia. Lisboa: Edições 70, 2010a.

ESPOSITO, Roberto. Communitas: the origin and destiny of community. Stanford: Stanford University Press, 2010b.

ESPOSITO, Roberto. Immunitas: the protection and negation of life. Cambridge: Polity, 2011.

FOUCAULT, Michel. Truth and power. In: Colin Gordon (org.). Michel Foucault. Power/knowledge: selected interviews and other writings, 1972-1977. New York: Pantheon, 1980a. p. 109-133.

FOUCAULT, Michel. The confession of the flesh. In: Colin Gordon (org.). Michel Foucault. Power/knowledge: selected interviews and other writings, 1972-1977. New York: Pantheon Books, 1980b. p. 194-228.

FOUCAULT, Michel. História da sexualidade - I: a vontade de saber. Lisboa: Relógio D’Água, 1994.

FOUCAULT, Michel. Les anormaux: cours au Collège de France, 1974-1975. Paris: Ehess, Gallimard, Seuil, 1999.

FOUCAULT, Michel. A ordem do discurso: aula inaugural no Collège de France, pronunciada em 2 de dezembro de 1970. Lisboa: Relógio D’Água, 2005.

FOUCAULT, Michel. É preciso defender a sociedade: curso no Collège de France (1975-1976). Lisboa: Livros do Brasil, 2006.

FOUCAULT, Michel. Nascimento da biopolitica. Lisboa: Edições 70, 2010 [ed. orig.: 2004].

FOUCAULT, Michel. Du gouvernement des vivants: Cours au Collège de France, 1979-1980. Paris: Ehess, Gallimard, Seuil, 2012.

KUHN, Thomas. A estrutura das revoluções cientificas. Lisboa: Guerra e Paz, 2009 [ed. orig.: 1962].

LAW, John. After method: mess in social science research. London: Routledge, 2004.

MOL, Annemarie. The body multiple: ontology in medical practice. Durham: Duke University Press, 2002. 
RAFFNSØE, Sverre; GUDMAND-HØYER, Marius; THANING, Morten S. What is a dispositive? Foucault's historical mappings of the networks of social reality. 2014. $<$ http://openarchive.cbs.dk/bitstream/handle/10398/9077/Raffnsoe.pdf? sequence=1>.

SCHMITT, Carl. Political Theology: four chapters on the concept of sovereignty. Chicago e London: University of Chicago Press, 2005 [ed. orig.: 1922].

SCHRAM, Sanford F. Return to politics: perestroika, phronesis, and post-paradigmatic political science. In: Sanford F. Schram; Brian Caterino (orgs.). Making political science matter: debating knowledge, research and method. New York: New York University Press, 2006. p. 17-32.

SIMMEL, Georg. The sociology of Georg Simmel. Glencoe: The Free Press, s. d.

SIMMEL, Georg. Les pauvres. Paris: PUF, 2008 [ed. orig.: 1908].

Recebido: 16 mar. 2018

Aceito: 08 out. 2018

Publicado: 01 mar. 2019

Endereço do autor:

João Aldeia

Universidade de Coimbra

Centro de Ecologia Funcional

Departamento de Ciências da Vida

Calçada Martim de Freitas

3000-456 Coimbra, Portugal

JOÃO ALDEIA <alvesaldeia@gmail.com>

Doutor em Sociologia pela Faculdade de Economia da Universidade de Coimbra, com o acolhimento científico do Centro de Estudos Sociais da Universidade de Coimbra (Coimbra, Portugal).

Orcid: http://orcid.org/0000-0002-8047-2694 